Indexed by

\title{
Scopus
}

\section{NUMERICAL EVALUATION OF SEISMIC PERFORMANCE OF CORRUGATED-PLATE SHAPED STEEL TUBES}

Crossref

KOBSON

Foogle

\section{Qusay Al-Kaseasbeh}

Deptartment of Civil and Environmental Engineering, Mutah University,

Jordan

\author{
Ahmed Albarram \\ Deptartment of Civil,Engineering, \\ Mustansiriyah University, \\ Iraq
}

Key words: corrugated-plate, steel columns, seismic, bridge, buckling doi:10.5937/jaes0-32490

Cite article:

Al-Kaseasbeh Q., Albarram A. (2022) NUMERICAL EVALUATION OF SEISMIC PERFORMANCE OF CORRUGATED-PLATE SHAPED STEEL TUBES, Journal of Applied Engineering Science, 20(2), 315 - 320, DOI:10.5937/ jaes0-32490

Online aceess of full paper is available at: www.engineeringscience.rs/browse-issues 


\title{
NUMERICAL EVALUATION OF SEISMIC PERFORMANCE OF CORRUGATED-PLATE SHAPED STEEL TUBES
}

\author{
Qusay Al-Kaseasbeh ${ }^{1, *}$, Ahmed Albarram ${ }^{2}$ \\ ${ }^{1}$ Deptartment of Civil and Environmental Engineering, Mutah University, Jordan \\ ${ }^{2}$ Deptartment of Civil Engineering, Mustansiriyah University, Iraq
}

The current work presents a unique study on the seismic performance of innovative corrugated-plate steel bridge piers. While several previous research was conducted on steel tubes with cross sections such as rounded or semi triangular plates, the seismic performance of such structural members with straight ribbed corrugation geometry under uniaxial cyclic loading remained a research gap. Thus, this research aims to present a new concept that could add a promising design to steel tubes under seismic effect. The seismic performance of such piers was numerically investigated in terms of the load-bearing capacity and local buckling. ABAQUS was employed to accomplish a series of finite element analyses on corrugated-plate steel bridge piers under constant axial dead load and lateral cyclic displacement. Three different geometries of corrugated-shaped steel tubes (i.e., C60, C80, and C146 mm deep) along with four different thicknesses (i.e., 6, 8, 10, and $12 \mathrm{~mm}$ ) were investigated and compared to the traditional circular-shaped steel tubes (i.e., Cir) having same thicknesses and outer diameter. The results revealed that the innovative corrugated-plate steel bridge piers offered $20 \%$ greater load-bearing capacity and $66 \%$ more ductility compared to their companions of circular-shaped steel tubes. It was interesting to notice that the peak value of the load-bearing capacity of the C146 column was greater than those of the C80 and C60 columns by $7 \%$ and 10\%, respectively. Furthermore, the local buckling was generally seen less severe amongst corrugated-plate steel bridge piers. This research raises the importance of corrugated-plate sections used in bridge piers over circular shapes owing to their advantages in strength and aestheticism.

Key words: corrugated-plate, steel columns, seismic, bridge, buckling

\section{INTRODUCTION}

In the last few decades, thin-walled steel structures have been widely applied in engineering structures owing to their favorable seismic performance in regions which are exposed to severe earthquakes [1-5]. Due to their high strength, light-weight, ductility, and torsional rigidity, thin-walled steel structures are used in numerous modern applications such as urban highway bridge systems where the constructional space is limited [2-4,6-9]. In the event of heavy earthquakes, thin-walled steel tubular cantilever bridge piers are vulnerable to local and overall interaction buckling damage [1-4,9]. Consequently, a significant degradation in the load-bearing capacity and ductility takes place $[1-4,10,11]$. Such bridge piers are affected by radius-to-thickness ratio parameter/widthto-thickness ratio parameter, and slenderness ratio parameter [1-4,9]. Since the late 1950s, the introduction of the corrugation to the structural members have been attracted more attention in aerospace, nuclear reactors, transportation, and civil engineering structures including buildings and bridges [12,13]. Many studies have revealed the efficiency of the corrugated structures over circular and rectangular cross-sections in energy absorption, weight reduction and stiffness improvement which are high demand in the event of severe earthquakes [1-4,12,14].Moreover, the manufacture or fabrication process of the corrugated structures becomes more affordable with advanced manufacturing technology such as 3D-printing technology [12]. Therefore, cor- rugated thin-walled steel tubular columns are believed to have an improvement in the overall seismic performance including the load-bearing capacity and the local buckling under seismic loadings. Steel tubes with corrugated shapes have been attractive topic for several research due to the lack of relative studies in the past. However, all available recent studies focused on the performance of steel tubes with either rounded or semi triangular plates [15-18]. More importantly, the axial behavior (static condition) prevailed the literature. Thus, the seismic behavior of steel tubes with new cross-section like straight ribbed corrugation (see Fig 1c) remained a research gap that needs to be bridged. For this reason, the current study aims to highlight the potential influence of usage of innovative corrugated plate in steel bridge piers. The authors herein believe that such cross-section would advance the performance of bridge piers in seismic zones in terms of load-bearing capacity, and buckling mode. A number of steel bridge piers subjected to constant axial dead load and lateral cyclic displacement are numerically analyzed using ABAQUS 6.14/standard. The parametric study centered around the configuration of bridge piers (from circular to corrugated) and different thicknesses of thin-walled steel tubes. The finite element (FE) results suggested a greater load-bearing capacity and ductility of bridge piers having corrugated-shaped than those with circular sections. Moreover, the superior performance in results was reported as the geometry of corrugated-shaped was made deeper. The current 
findings emphasize the significance of corrugated-plate sections used in bridge piers over circular shapes owing to their advantages in strength and aestheticism.

\section{FINITE ELEMENT (FE) MODELING}

\section{Geometry specification and mesh analysis}

A total of 16 steel tubular piers were modelled and analyzed by ABAQUS 6.14/standard. The FE program involved 4 circular-shaped and 12 corrugated-shaped steel tubes with constant height and outer diameter of $3403 \mathrm{~mm}$ and $900 \mathrm{~mm}$, respectively. Both material and non-linear geometry were addressed using the linear kinematic hardening model, von Mises yield surface, and associated plastic flow rule $[1,4]$. This approach is the most convenient model to represent the inelastic behavior of materials subjected to cyclic loading [19]. All FE models were assumed to be made from the same carbon steel ASTM A36 [20]. To achieve more efficient analysis in terms of time and results, shell elements with reduced integration four-node (SR4) were adopted for this purpose. The geometry of all FE models was divided into three segments along their heights with different mesh number and size (see Fig 1b). That included 26 shell elements for the lower segment (equal to the outer diameter, D), 14 shell elements for the middle segment whilst the upper part (i.e., $h-2 D$ ) was provided with a mesh size of $90 \mathrm{~mm}$. Fifty elements were adopted in the circumferential direction in all models. Applying such mesh properties was previously asserted to be the most effective method at predicting the accuracy in the hysteretic behavior and bucking mode $[1,4]$. The column slenderness ratio $(\lambda)$ was measured through the following equation:

$$
\lambda=\frac{2 h}{r} \frac{1}{\pi} \sqrt{\frac{\sigma_{y}}{E}}
$$

where $\mathrm{h}$ is the column height (3403 mm), oy is the yield stress taken as 289.6 MPa, and E is the Young's modulus (206 GPa).

\section{Parametric study}

The parametric study consisted of the geometries of steel tubes along with the radius-to-thickness ratio parameter $\left(R_{t}\right)$. Three different geometries of corrugated-shaped steel tubes (i.e., C60, C80, and C146 mm deep) were considered, whereas the average corrugated-shaped width to depth $(\mathrm{b} / \mathrm{d})$ is $2.58,1.7$ and 0.67 , respectively, as $b=(b 1+b 2) / 2$. Full sketches with details are illustrated in Fig 1c. Such corrugated-shaped sections are commercially produced by Kingspan company which is based in UK [21]. Each of those corrugated-shaped geometry was modelled with four different thicknesses (i.e., 6, 8, 10, and $12 \mathrm{~mm}$ ). The FE program aimed at comparing the results obtained from non-conventional geometries of steel tubes with the control case having

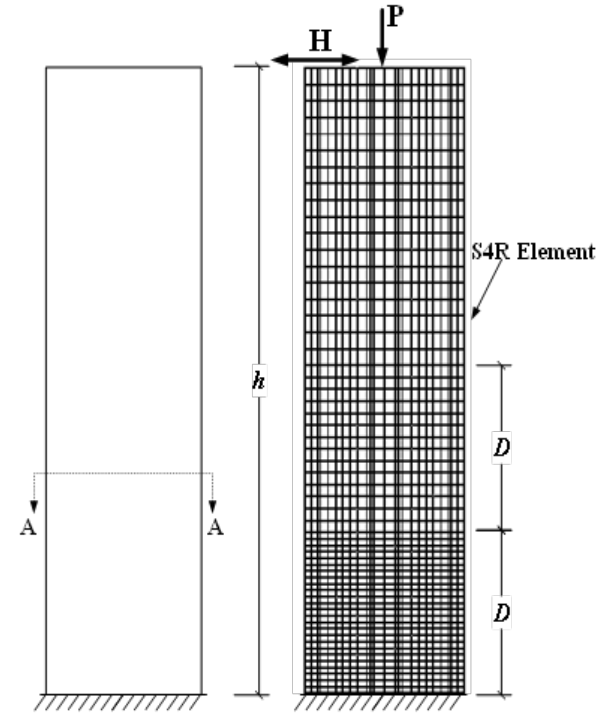

(a) (b)

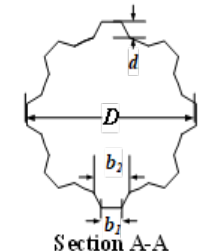

(c)

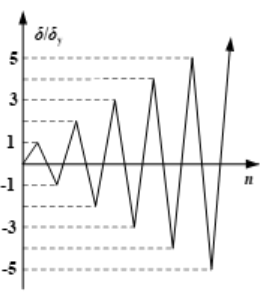

(d)
Figure 1: FE Model: (a) Column, (b) Meshing, (c) Corrugated section, and (d) Loading

traditional circular shape with the same thicknesses and outer diameter. Meanwhile, the radius-to-thickness parameter $(\mathrm{Rt})$ was determined from the following formula:

$R_{t}=\frac{D}{2 t} \frac{\sigma_{y}}{E} \sqrt{3\left(1-v^{2}\right)}$

where $D$ is the outer diameter $(900 \mathrm{~mm})$, $t$ is the plate thickness, and $v$ is the Poisson's ratio ( 0.3 for steel).

\section{Bundary condition and load application}

During the numerical analysis, the bottom end of all FE steel tubes was restricted from moving and rotating in all direction. At the top end, a unidirectional cyclic displacement was quasi-statically applied along with a constant axial dead load $(P)$ by means of a hypothetical reference point created in the middle and tied with the upper circumference using a multiple point control (MPC) beam constraint method. The constant axial load was assumed to be $12.4 \%$ of the yield load $\left(P_{y}\right)$, the latter parameter is defined by $\sigma_{y} A$, where $A$ is the cross-sectional area [22]. The lateral displacement was applied through one-cycle loading $(\mathrm{N})$ and raised gradually as a multiple of the yield displacement $\left(\delta_{y}\right)$ calculated in equation 3 and the lateral yield load in equation 4 as follows:

$$
\begin{aligned}
& \delta_{y}=\frac{H_{y} h^{3}}{3 E I} \\
& H_{y}=\left(\sigma_{y}-\frac{P}{A}\right) \frac{Z}{h}
\end{aligned}
$$


where $\mathbf{Z}$ is the section modulus of the column. Table 1 lists the relevant yield displacement and lateral yield load for the FE analyzed steel tubes.

\section{RESULTS AND DISCUSSION}

FE analyses were conducted to investigate the superior performance of corrugated-plate steel tubes with three different geometries (i.e., C60, C80, and C146 mm deep) along with four different thicknesses (i.e., 6, 8, 10, and $12 \mathrm{~mm}$ ) over the traditional circular-shaped ones having same thicknesses and outer diameter. Case studies including hysteretic behavior, damage deformation and energy absorption are discussed in details in forthcoming sections.

Table 1: Ultimate Load-bearing and Ductility Capacities

\begin{tabular}{|c|c|c|c|c|}
\hline Column & $\mathrm{H}_{v}(\mathrm{kN})$ & $\delta_{v}(\mathrm{~mm})$ & $\mathrm{H} / \mathrm{H}_{v}$ & $\delta_{m} / \delta_{v}$ \\
\hline Cir-t6 & 278.91 & 10.56 & 1.331 & 1.92 \\
\hline Cir-t8 & 369.41 & 10.56 & 1.389 & 2.04 \\
\hline Cir-t10 & 458.68 & 10.56 & 1.439 & 2.34 \\
\hline Cir-t12 & 546.75 & 10.56 & 1.488 & 2.76 \\
\hline C60-t6 & 271.28 & 10.56 & 1.627 & 5.00 \\
\hline C60-t8 & 357.41 & 10.56 & 1.668 & 6.00 \\
\hline C60-t10 & 445.07 & 10.56 & 1.692 & 7.00 \\
\hline C60-t12 & 529.89 & 10.56 & 1.742 & 8.00 \\
\hline C80-t6 & 269.65 & 10.56 & 1.676 & 5.52 \\
\hline C80-t8 & 359.11 & 10.56 & 1.698 & 7.00 \\
\hline C80-t10 & 441.93 & 10.56 & 1.742 & 7.00 \\
\hline C80-t12 & 525.87 & 10.56 & 1.770 & 8.00 \\
\hline C146-t6 & 259.80 & 10.56 & 1.776 & 5.00 \\
\hline C146-t8 & 343.06 & 10.56 & 1.825 & 7.00 \\
\hline C146-t10 & 424.67 & 10.56 & 1.874 & 8.00 \\
\hline C146-t12 & 504.67 & 10.56 & 1.899 & 8.00 \\
\hline
\end{tabular}

\section{Hysteric behavior}

To facilitate a meaningful comparison, the normalized lateral load $\left(\mathrm{H} / \mathrm{H}_{\mathrm{y}}\right)$ versus normalized lateral displacement $\left(\delta / \delta_{y}\right)$ loops of all analyzed columns under the one-cycle lateral displacement program (see Fig 1d), and constant axial dead load and lateral cyclic displacement are illustrated in Fig 2. In this figure, Hy and סy designate, respectively, the lateral yield load and the yield displacement. The long dash dot black, the solid orange, and the square dot green lines denote C60, C80, and $\mathrm{C} 146$ respectively, while the sloid dark red stands for the Cir steel tube. The plotted hysteresis loops in Fig 2 show a remarkable improvement in the ultimate load-bearing capacity and the ductility of the innovative corrugated-plate steel columns. In the case of the innovative corrugated-plate steel columns, a significant increase at an average of $20 \%$ in ultimate load-bear- ing capacity and $66 \%$ in ductile behavior is noticed as compared to traditional circular-shaped steel columns. In particular, the C146-t8 column shows $24 \%$ and $71 \%$, respectively, better overall behavior than its counterpart Cir-t8 column which highlight the superiority of the newly proposed corrugated-plate steel cross sections. Moreover, the C146 column with different thickness shows more improvement than both $\mathrm{C} 60$ and $\mathrm{C} 80$ columns by $7 \%$ and $10 \%$, respectively, at the same plate thickness emphasizing the importance of the corrugation depth parameter. Furthermore, the lateral load versus lateral displacement positive envelope curves of the innovative corrugated-plate and traditional circular-shaped steel columns are illustrated in Fig 3. As seen, the post-buckling behavior (i.e., buckling after the peak point) of the innovative corrugated-plate steel columns was improved compared to the traditional circular-shaped steel ones.
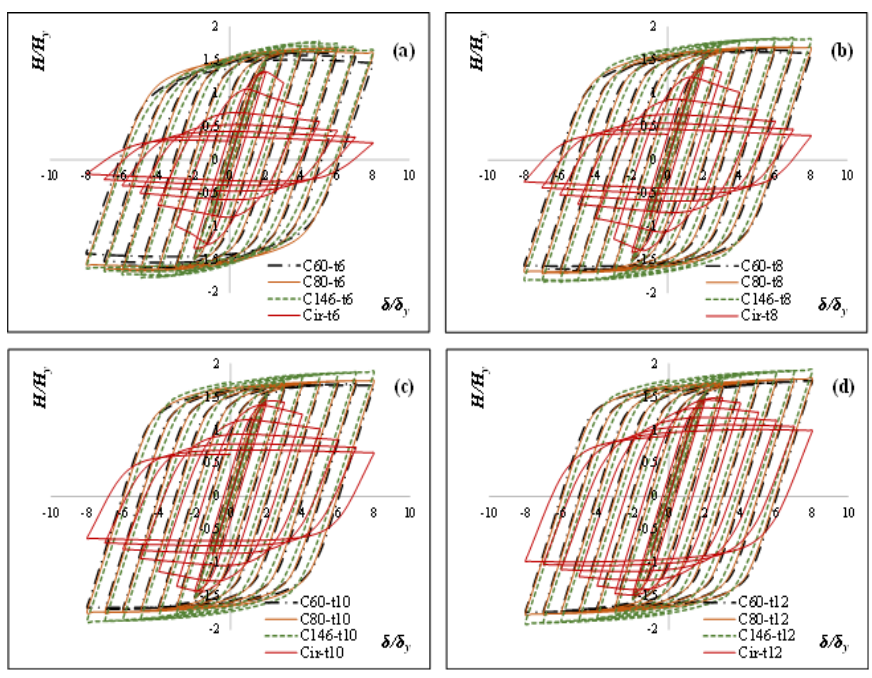

Figure 2: Lateral Load $\left(H / H_{y}\right)$ vs. Lateral Displacement $\left(\delta / \delta_{y}\right)$ Loops

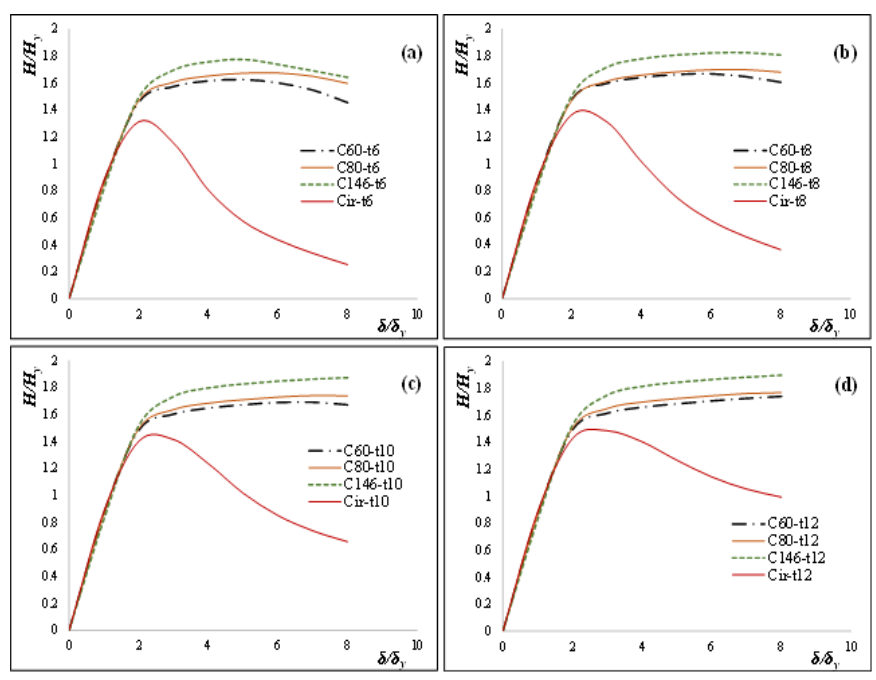

Figure 3: Lateral Load vs. Displacement Positive Envelope Curves 
For instance, conventional circular-shaped steel columns show the ultimate load-bearing capacity when $\delta / \delta y$ is in a range of 1.92 to 2.76 , and the strength drop happens at an average rate of $20 \%$ after the peak point. In contrast, the innovative corrugated-plate steel columns have the ultimate load-bearing capacity when $\delta / \delta y$ is approximately 5 to 8 , and the strength is decreasing after the peak point at a rate of $0-4 \%$ (See Table 1$)$.

\section{Damage deformation}

At the end of the FE analysis, the failure mode of all FE models was observed. In case of circular-shaped steel columns, local buckling with elephant-foot bulge deformation was seen in such tests adjacent to the fixed end of columns (see Fig 4). This common failure mode amongst steel tubes with circular cross-sections usually happens at early stage of loading due to the inability of circular shapes to seize the damage tendency. As a result, steel tubes encounter a significant degradation in both load-bearing capacity and ductility [16,23,24]. Hysteretic loops besides envelope curves shown in Figs 2 and 3 , respectively clearly reveal a steep decline in the normalized lateral load $\left(\mathrm{H} / \mathrm{H}_{\mathrm{y}}\right)$ in steel tubes with lower thicknesses during the ongoing test (i.e., 6 and 8 $\mathrm{mm}$ ). Despite the slope tendency was mitigated among steel tubes with higher thicknesses (i.e., 10 and $12 \mathrm{~mm}$ ), strength and ductility deterioration remained a drawback. In contrast, the elephant-foot bulge failure was not captured in corrugated-shaped steel columns as presented in Fig 4. The severity of damage was noticed less in the corrugated-plate steel columns due to the corrugation geometry which forms longitudinal stiffeners along the column height. Using straight ribbed shapes were capable of not limiting the damage in particular zone, where the deeper corrugated geometry used (i.e., C146), the less damage formation appeared. Moreover, steel tubes with corrugated geometry were more effective than circular sections at controlling the degradation in both normalized lateral loads $(\mathrm{H} / \mathrm{Hy})$ and ductility for the same cyclic loading history (see hysteretic loops in Fig 2 and envelope curves in Fig 3). It can be concluded that using corrugated cross-sections would strengthen the steel piers and limit the damage tendency in the events of earthquakes leading towards saving lives and relevant structures.

\section{Energy absorption}

The energy dissipation capacity of the structural element is an important index of the structure's resistance to the seismic loading (i.e., earthquakes) [25]. Moreover, the ductility plays a significant role in the seismic design which is related to the energy dissipation capacity of the structural system induced by nonlinear behavior [26] In the purpose of evaluating the seismic performance of the whole structure in the seismic-prone areas, it is very important to quantify the energy dissipation capacity of each structural component [27]. The amount of the energy that can be dissipated by the structural element depends on the number, amplitude, and the distribution of the loading cycles throughout the loading history [25]. To investigate the inelastic cyclic performance of all corrugated-shaped steel tubes (i.e., C60, C80, and C146 $\mathrm{mm}$ deep) along with four different thicknesses (i.e., 6, 8,10 , and $12 \mathrm{~mm}$ ) which is compared to the traditional circular-shaped steel tubes (i.e., Cir), the plastic damage energy dissipation is calculated and illustrated in Fig 5.

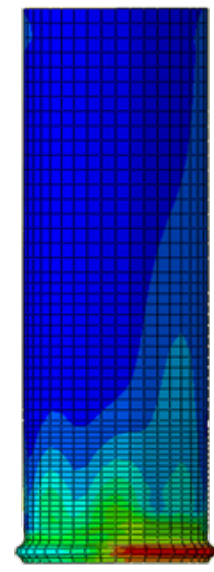

Cir-t6

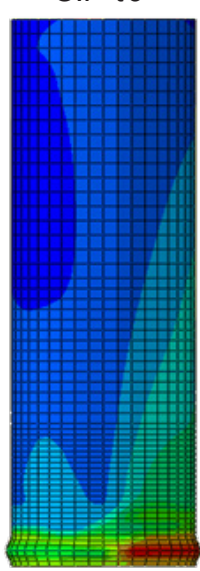

Cir-t10

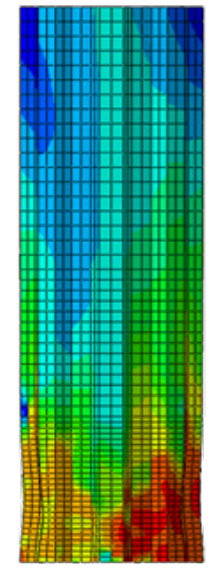

c60-t6

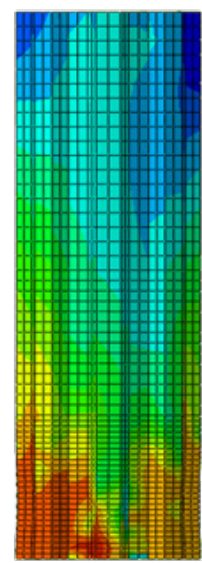

C60-t10

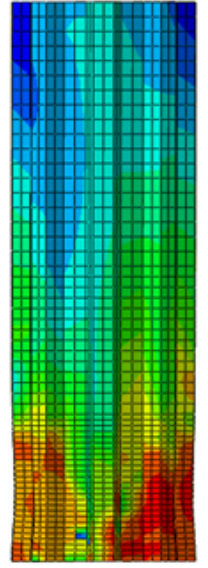

c80-t6

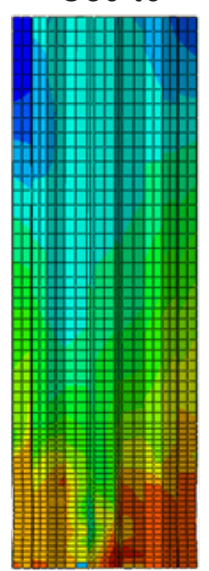

C80-t10

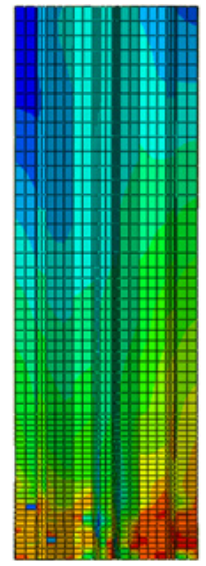

C146-t6

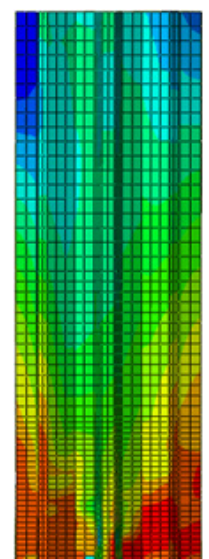

C146-t10
Figure 4: Local Damage Deformation of the Columns

A normalized energy absorption capacity $(E)$ is evaluated as follows [28]:

$$
E=\frac{2}{H_{y} \delta_{y}} \sum_{i=1}^{n} E_{i}
$$

In Equation. (5), $E_{i}=$ energy absorption in the half-cycle, $n=$ number of half-cycles (one half-cycle is defined from any zero-lateral load to the subsequent zero-lateral load). By a different technique, the cumulative plastic damage energy is evaluated as the enclosed area under the normalized hysteretic curves of cyclic loading. As seen in Fig 5, all corrugated-shaped steel tubes have dissipated $54 \%$ more energy than those of traditional circular-shaped steel tubes. These interesting findings indicate that the corrugated geometry makes the columns 
more ductile under the cyclic loading. Once again, steel piers with non-traditional geometry are proved to offer superior properties compared to the common cross-sections.

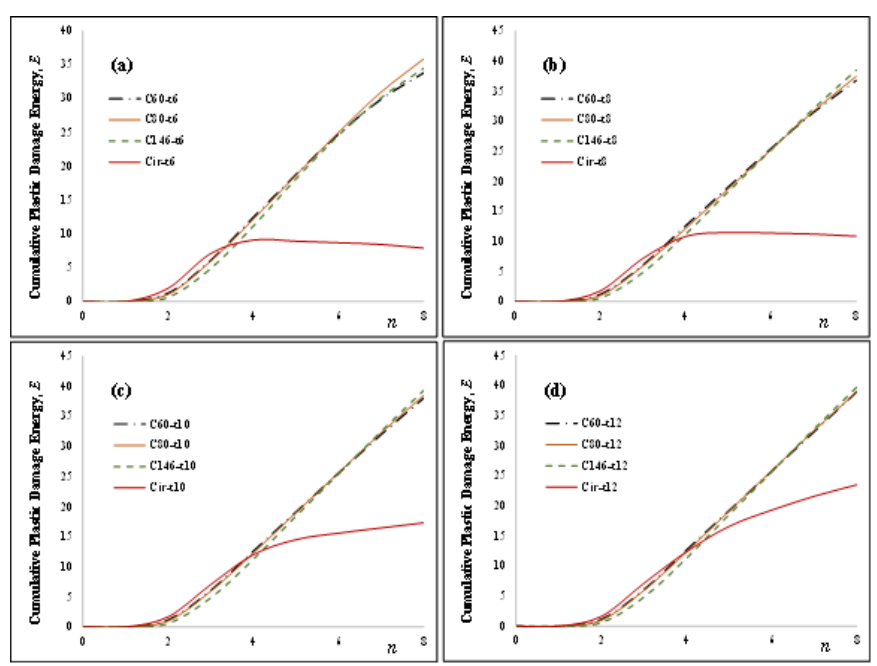

Figure 5: Energy Absorption Capacity of the Columns

\section{CONCLUSIONS}

The present work provided a valuable insight into the behavior of steel bridge piers associated with non-traditional cross-section under seismic effect. A total of 16 steel bridge piers with height and outer diameter of $3403 \mathrm{~mm}$ and $900 \mathrm{~mm}$, respectively were numerically analyzed under constant axial deal load and unidirectional cyclic displacement. The FE program investigated three different geometries of corrugated-shaped steel tubes (i.e., C60, $\mathrm{C} 80$, and C146 $\mathrm{mm}$ deep) along with four different thicknesses (i.e., 6, 8, 10, and $12 \mathrm{~mm}$ ) and compared to the traditional circular-shaped steel tubes (i.e., Cir) with the same thicknesses. Some remarkable results are listed below:

- In general, the use of corrugated-shaped plates over circular sections resulted in increase in both load-bearing capacity and ductility by as much as $20 \%$ and $66 \%$, respectively. For instance, steel tubes with corrugated geometry of $146 \mathrm{~mm}$ deep and plate thickness of $8 \mathrm{~mm}$ offered $24 \%$ and $71 \%$ greater normalized lateral load $(\mathrm{H} / \mathrm{Hy})$ and ductility, respectively than its counterpart having circular section. FE results also indicated a favorable performance of corrugated shapes over circulars in terms of energy dissipation by $54 \%$.

- Steel bridge piers with $146 \mathrm{~mm}$ deep corrugated plates revealed greater performance in both load-bearing capacity and ductility than their counterparts having $60 \mathrm{~mm}$ and $80 \mathrm{~mm}$ deep corrugated plates. The improvement was reported at $7 \%$ and $10 \%$ regarding the normalized lateral loads $(\mathrm{H} / \mathrm{Hy})$ and ductility, respectively.
- $\quad$ Steel bridge piers with circular plates (regardless the amount of thickness) were susceptible to end up with elephant-foot bulge failure. This failure mode was jointed with a remarkable degradation in both load bearing capacity and ductility. Contrarily, using any corrugation geometry prevented such unfavorable failure mode from occurring and limiting the damage severity of steel tubes. As a result, steel tubes experienced a significant improvement in both load bearing capacity and ductility as stated before.

- $\quad$ FE results suggested that C146 mm deep corrugated plates was more capable than any other shape of suppressing the damage patterns along the height of bridge piers. This was attributed to the deep straight ribs which formed longitudinal stiffeners along the height of columns. On whole, the concept of using corrugated-shaped plates in bridge piers will substantially serve the constructional field structurally and aesthetically.

\section{ACKNOWLEDGMENTS}

The first author would like to thank Mutah University for their continuous support. Also, the second author is grateful to Mustansiriyah University for their academic support to accomplish the current research.

\section{REFERENCES}

1. Al-Kaseasbeh Q, Mamaghani IHP. Buckling Strength and Ductility Evaluation of Thin-Walled Steel Tubular Columns with Uniform and Graded Thickness under Cyclic Loading. J Bridg Eng 2018;24:04018105. doi:10.1061/(ASCE)BE.1943-5592.0001324.

2. Al-Kaseasbeh $Q$, Mamaghani IHP. Thin-Walled Steel Stiffened Square Box Columns with Uniform and Graded Thickness under Bidirectional Cyclic Loading. Eng Struct 2020;219:110919. doi:10.1016/j.engstruct.2020.110919.

3. Al-Kaseasbeh Q, Mamaghani IHP. Buckling strength and ductility evaluation of thin-walled steel stiffened square box columns with uniform and graded thickness under cyclic loading. Eng Struct 2019;186:498507. doi:10.1016/j.engstruct.2019.02.026.

4. Al-Kaseasbeh Q, Mamaghani IHP. Thin-Walled Steel Tubular Circular Columns with Uniform and Graded Thickness under Bidirectional Cyclic Loading. Thin-Walled Struct 2019;145:106449. doi:10.1016/j. tws.2019.106449.

5. Zhu JS, Guo YL, Wang MZ, Yang X, Zhu BL. Strength design of concrete-infilled double steel corrugated-plate walls under uniform compressions. Thin-Walled Struct 2019;141:153-74. doi:10.1016/j. tws.2019.02.021.

6. Wang $Y$, Mahendran M, Shahbazian A. Fire Performance of Thin-Walled Steel Structures. 2020. doi:10.1201/9781351011815. 
7. Kodur VKR, Naser MZ. Designing steel bridges for fire safety. J Constr Steel Res 2019;156:46-53. doi:10.1016/j.jcsr.2019.01.020.

8. Al-Kaseasbeh Q, Mamaghani IHP. Buckling Strength and Ductility Evaluation of Thin-Walled Steel Tubular Columns Under Cyclic Loading. 10th Int. Conf. Short Mediu. Span Bridg., Quebec City, Canada: 2018.

9. Mamaghani IHP, Ahmad F, Dorose B. Strength and Ductility Evaluation of Steel Tubular Columns under Cyclic Multiaxial Loading. ISTS15 - 15th Int. Symp. Tubul. Struct., Rio, Brasil: 2015.

10. Aoki T, Susantha KAS. Seismic Performance of Rectangular-Shaped Steel Piers under Cyclic Loading. J Struct Eng 2005;131:240-9. doi:10.1061/ (ASCE)0733-9445(2005)131:2(240).

11. Xu SH, Qin GC, Zhang ZX. Experimental Research on Hysteretic Characteristics of Steel Plates Artificially Corroded by Neutral Salt Spray. Adv Mater Sci Eng 2016;2016. doi:10.1155/2016/7645763.

12. Ha NS, Lu G. Thin-walled corrugated structures: A review of crashworthiness designs and energy absorption characteristics. Thin-Walled Struct 2020;157:106995. doi:10.1016/j.tws.2020.106995.

13. Ucak A, Tsopelas P. Seismic behavior of thinwalled corrugated bridge piers 2004.

14. Albarram A, Qureshi J, Abbas A. Effect of Rib Geometry in Steel-Concrete Composite Beams with Deep Profiled Sheeting. Int J Steel Struct 2020;20:931-53. doi:10.1007/s13296-020-00333-5.

15. Fang $Y$, Wang $Y$, Hou C, Lu B. CFDST stub columns with galvanized corrugated steel tubes: Concept and axial behaviour. Thin-Walled Struct 2020;157:107116. doi:10.1016/j.tws.2020.107116.

16. Wang C, Yun Z, Kang J, Zhou Y, Chen M, Wu Y. Behavior of an innovative square composite column made of four steel tubes at the corners and corrugated steel batten plates on all sides. Adv Civ Eng 2019;2019. doi:10.1155/2019/2971962.

17. Yang L, Wang $Y$, Elchalakani M, Fang Y. Experimental behavior of concrete-filled corrugated steel tubular short columns under eccentric compression and non-uniform confinement. Eng Struct 2020;220:111009. doi:10.1016/j.engstruct.2020.111009.

18. Fang $Y$, Liu C, Yang $H$, Yang L. Axial behaviour of concrete-filled corrugated steel tubular column embedded with structural steel. J Constr Steel Res 2020;170:106064. doi:10.1016/j.jcsr.2020.106064.

19. Hibbit, Karlsson, Sorensen. ABAQUS 2014 Documnetation 2014.

20. ASTM. ASTM A36 / A36M - 14 Standard Specification for Carbon Structural Steel. ASTM Int West Conshohocken, PA 2014:12-4. doi:10.1520/A0036.
21. Kingspan. Multideck Technical Handbook: Manufactures of Multideck Composite Metal Decking. North Yorkshire, United Kingdom: 2011.

22. Nishikawa K, Yamamoto S, Natori T, Terao K, Yasunami $\mathrm{H}$, Terada M. Retrofitting for seismic upgrading of steel bridge columns. Eng Struct 1998;20:540-51. doi:10.1016/s0141-0296(97)00025-4.

23. Ding F, Liu Y, Lyu F, Lu D, Chen J. Cyclic loading tests of stirrup cage confined concrete-filled steel tube columns under high axial pressure. Eng Struct 2020;221:111048. doi:10.1016/j.engstruct.2020.111048.

24. Yang C, Zhao H, Sun Y, Zhao S. Compressive stressstrain model of cold-formed circular hollow section stub columns considering local buckling. ThinWalled Struct 2017;120:495-505. doi:10.1016/j. tws.2017.09.017.

25. Jiao Y, Yamada S, Kishiki S, Shimada Y. Evaluation of plastic energy dissipation capacity of steel beams suffering ductile fracture under various loading histories. Earthq Eng Struct Dyn 2011;40:1553-70. doi:10.1002/eqe.1103.

26. Reyes-Salazar A, Bojórquez E, Bojorquez J, Valenzuela-Beltran F, Llanes-Tizoc MD. Energy dissipation and local, story, and global ductility reduction factors in steel frames under vibrations produced by earthquakes. Shock Vib 2018;2018. doi:10.1155/2018/9713685.

27. Galé-Lamuela D, Donaire-Avila J, Escolano-Margarit D, González-Sanz G, Benavent-Climent A. Energy dissipation capacity of RC columns subjected to unidirectional and bidirectional seismic loading. COMPDYN Proc., vol. 2, National Technical University of Athens; 2019, p. 2316-31. doi:10.7712/120119.7078.19108.

28. Al-Kaseasbeh Q, Mamaghani IHP. Design and Cyclic Elastoplatic Analysis of Graded Thin-Walled Steel Tubular Columns with Enhanced Strength and Ductility. 6th IAJC Int. Conf., Orlando, FL: 2018.

Paper submitted: 30.05.2021.

Paper accepted: 4.12.2021.

This is an open access article distributed under the CC BY 4.0 terms and conditions. 